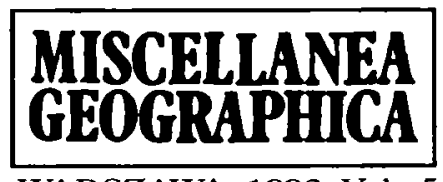

WARSZAWA 1992 Vol. 5

Witold Kusiński

\title{
REGIONAL DIFFERENTIATION OF THE URBANIZATION LEVEL IN POLAND
}

Urbanization is one of the notions most frequently used by representatives of many disciplines of sciences and by social activists. Almost all publications on population or settlement problems emphasize that the urbanization has become a phenomenon which permeates almost all spheres of social life, and that it has come to be a global and essentially irreversible phenomenon. Until recently, in the relevant literature narrow approach to this phenomenon prevailed - most frequently as a certain state of population relations that manifested itself in percentage of population living in towns. Today it is underlined that the notion of urbanization indicates a definite socio-economic process, as well as the state (level) attained in the course of this process.

Although there is no unanimity, and various views are presented on definition of urbanization as a process, there is a considerable agreement in opinions that it is... a complex social process consisting in transformation of great communities (a whole nation) from the traditional rural society into a more differentiated urban one"1, or it is "a transformation of the socio-spatial system of the whole society" 2 , or — presented in a more developed way - it is "a socio-economic process consisting in a concentration of population and considerably complex human activity over a small area, intensification of this activity, appearance of the complex settlement forms (agglomerations), and distribution of urban lifestyle and system of values" 3 .

\footnotetext{
${ }^{1}$ D z i e w oń s k i K., 1969, O nowy model sieci osadniczej i urbanizacji kraju (On New Model of Settlement Network and Urbanization of the Country, Sprawy Mieszkaniowe, Nos 2-3

${ }^{2}$ Labowit z S. Purdy R. Teritorial Differentiation and Social Change. American Journal of Economy and Sociology 1970 r. 29. Kusiński W. 1972 "Pojęcie i miemiki urbanizacji" (The Notion and Measures of Urbanization) Czasopismo Geograficzne Vol. 49 No. 41972 r.

${ }^{3}$ Leszczycki St., Wróbel A., 1967 "Statystyczne wskaźniki procesu urbanizacji". w: Problemy demografii Polski Ludowej" Warszawa 1967 (Statistical Indices of the Urbanization Process), in: Problems of Demography of the People's Poland, Warszawa 1967, Biblioteka Wiadomości Statystycznych, Vo. 4.
} 
While generalizing various definitions it can be stated that the urbanization is a universally observed process of transformation of the socio-economic-ecological system of society. It is also assumed that this system includes demographic, economic, social, cultural, ecological, legal and technical spheres of life of a society in the particular - and not only municipal - territory.

A considerable degree of conformity of various definitions of the urbanization phenomenon creates some convenience in research methodology. Thus, quite a clear definition of research object has been obtained. However, the difficulties arise because of lack of one sufficiently adequate index (standard) of the acquired level of urbanization. The most often applied standard of the urbanization level is a percentage of population living in towns. Sometimes, this index is supplemented with information on a percentage of population living in big cities. Now and then, attempts are made to estimate the level of urbanization of an area by comparing the type of builtup, degree of communal installations, density of urban network, process of development of urban complexes (city agglomerations, conurbations), size of areas occupied by cities or the role of the city areas in the overall area of a region or of a country. While investigating the above-mentioned features, the spatial aspect of urbanization is being exposed.

Some researchers put a great emphasis on the investigation of participation of inhabitants employed in the non-agricultural fields of economy because they assume that people employed outside of agriculture concentrate mostly in cities and in this way the importance of economic aspect of urbanization is stressed.

The forms of human behaviour, ways of nutrition, dressing, leisure-time spending and so on, are also investigated. In this way, a sociological aspect is emphasized. In some papers legal and ecological aspects are stressed.

Taking into account that nowadays the majority of researchers who investigate the urbanization phenomenon share a view that it is a considerably complex and multiplex process, there is a need to carry out investigation on urbanization in a deep, many-sided way, with consideration given to many features and use of various standards. This conviction manifested itself more than once in attempts to work out a complex index of urbanization with respect to information about a greater number of characteristics. It turned out, however, that a simple formalization of diverse references concerning various sides of the urbanization processes is a cause of obliteration of many qualitative features which in turn impoverishes the results obtained. It also happens that parametrized information on many features of the urbanization process cannot be transformed into an integrated index, or the result obtained cannot be interpreted and clearly described in a proper way.

In the paper presented, an attempt is made to determine a level of urbanization of the particular voivodships in Poland according to the data of $1987 / 88$, taking into account a degree of transformation of the selected spheres of social life of our country under the influence of socio-economic development which has its source in the growing social division of labour. 
The course of action aimed at defining the urbanization level is as follows: on the basis of the official statistical data, by way of simple calculations, we determine indices of twelve features which permit us to set a degree of urbanization of the particular voivodships within the framework of four aspects of urbanization. This can be attained through a determination of place (position) of every voivodship in the group of all the voivodships in respect of density of population, percentage of city dwellers, percentage of population in the productive age (these three indices characterize a demographic aspect); employment in the socialized economy (this index, because of lack of the relevant data in the statistical yearbook is replaced by the index of employment in the non-agricultural professions; now that many private non-agricultural production and service enterprises appeared, using an index of employment in socialized economy would be devoid of much sense), value of capital goods (blns zlotys) per $1 \mathrm{~km}^{2}$ of area, and number of hectares of arable land per capita (economic aspect); number of rooms per 1000 dwellers, value of service sold (thous. zlotys) per inhabitant, number of newspapers sold per inhabitant (social aspect); average size of the territory "served" by one town, density of railway network (number of kilometers of railroads per $100 \mathrm{~km}^{2}$ ), density of network of roads of hard surface (number of kilometres of road per $100 \mathrm{~km}^{2}$ of voivodship area) (spatial aspect).

The indices obtained are ranged in decreasing order (excepting the index of number of hectares of arable land per one inhabitant which are ranked in the reverse order) from 1 to 49 , and are compared with the national index. This is the way to find out whether a voivodship is ranked high or low. Then the position of each voividship is being summed up. A sum of positions of each voivodship considered in respect of the particular features (to simplify, this sum can be divided by the number of features) is a basis for rating of each voivodship in a group of voivodships of very high, high, average, low and very low level of urbanization. It is not, of course, a precise measurement, but objective enough for determining a degree of urbanization and defining every voivodship in the group.

The urbanization process in Poland over the past 40 years has been considerably accelerated, and within a scope of some features considered not only on the country's scale, this phenomenon has reached a high level. This process has not been going on with the same speed throughout the country.

The socio-economic transformations manifest themselves very strongly in change in population structure, and above all in the size of human agglomerations and density of population. At the same time, increase of population density reflects a progressing urbanization. It is a consequence of location in towns of the majority of non-agricultural enterprises in which the emigrants from villages seek an employment. Situating the non-agricultural enterprises in the rural areas attracts people, too, and causes an increase in density of population. Such enclaves of an increased density of population evidence, among others, a progressing urbanization of the countryside.

The population in Poland is distributed irregularly, with the average allPoland's density amounting to 120 persons per $1 \mathrm{~km}^{2}$; in the Suwałki voivodship 
this index has not reached 45 persons $/ \mathrm{km}^{2}$, but in Łodź voivodship it almost amounts to 750 persons $/ \mathrm{km}^{2}$. Assuming — as it had some time ago been done in the course of investigations of metropolitan areas by IGiPZ PAN (Institute of Geography and Spatial Economy of the Polish Academy of Sciences) - that in Poland an average population density exceeding 150 per sons by $1 \mathrm{~km}^{2}$ proves the existence of urbanized areas ${ }^{4}$, it will turn out that in 11 voivodships this index is exceeded, sometimes considerably; at the same time, in the seven remaining voivodships it does not even reach half of all-Poland's index. Should slightly lower index of the population density be accepted (but higher than the average one) as a determinant of existence of the urbanized areas, and the existence of the urban agglomeration in the voivodships area be confirmed, a number of voivodships with a relatively high index of urbanization would come to 14 (Fig. 1).

A slightly different picture is obtained in using the index of the urban population in the voivodship population. The average index of the share of urban population in Poland amounts to $62 \%$. It is twice as high as before the Second World War, at the same time being not far away from the indices of a number of West European countries. The range of extreme values of index is nevertheless considerable. In the Zamość voivodship it comes to only $27.4 \%$, but in Łódź voivodship it is over $93 \%$, i.e. 3.4 times higher (Fig. 2). In respect of percentage of urban population, Poland is divided into two parts: Western one in which (except Słupsk, Piła, Leszno and Opole) the population amounts to over $60 \%$ in the particular voivodships, and Eastern comprising voivodships which had been under Russian and Austrian Partitions in the past, and territories of the former East Prussia. In this part of Poland, a percentage of urban population in the particular voivodships does not reach $60 \%$ (except for such voivodships as Warsaw, Łódź, Katowice, and Cracow), and in 12 voivodshps - not even $40 \%$.

In determining the degree of urbanization in the demographic aspect, of particular importance can be an index of the share of population in the productive age, beceuse in the process of urbanization, the transformations of a structure of population age are revealed. Areas of more developed non-agricultural sectors of economy are more attractive in the economic and social sense, attract more population in the working-ability age, and they are often marked by a diminished birth rate. Spatial differentiation of the index of share of population in the working-ability age, regardless of the range of extreme figures being not so great as in case of population density and share of urban population, is distinct (Warsaw voivodship $61,9 \%$, Bielsk Podlaski 53.6\%) (Fig. 3). An increased share of population in the working-ability age can be seen in all voivodships of the SouthEastern Poland - from Cracow voivodship to the state border, in three seaside voivodships, namely Szczecin, Koszalin and Gdańsk and in Warsaw, Łódź, Poznań and Olsztyn voivodships. Instead, in the voivodships of Central, Eastern

\footnotetext{
${ }^{4}$ Another denominator of urbanization in the economic aspect can be an index of comminuting of farms, and chiefly the smallest ones (below $2 \mathrm{ha}$ ).
} 
and South-Eastern Poland there is significantly less population in the productive age. It is interesting to note that spatial differentiation of the share of population in the productive age is similar to differentiation of an index of people employed in the socialized sector, which - as it was underlined earlier - was applied as a substitute index of the share of people employed in the non-agricultural sectors of economy (Fig. 4). This index varies from 197 persons per 1000 inhabitants in Łożma voivodship to almost 400 in Katowice voivodship.

Another indicator of the level of urbanization in an economic aspect is an index of outfit of voivodships with capital goods (Fig. 5). The differentiation of this index is very high. The highest ratio of capital goods has been noted in Warsaw voivodship ( 2.74 billion zlotys $/ \mathrm{km}^{2}$ ), where it is almost 25 times higher than in Suwalki voivodship ( 0.11 billion zlotys $\left./ \mathrm{km}^{2}\right)$. The application of the index of the stock of capital goods in defining urbanization level, may raise many doubts as the posession of capital goods reflects above all a degree of economic development and civilization level. We assume, however, that urbanized terrains are marked by a higher civilization level and a greater complexity and level of technical facilities.

A reverse of a picture of the stock of capital goods in the particular voivodships, which reflects development of the non-agricultural sectors of economy including various branches of technical and economic as well as social infrastructure, is a picture of spatial differentiation of an index of area of arable land per 1 inhabitant of a voivodship. This index allows us to distnguish the most agricultural voivodships and having considerable possibilities (particularly as far as an area of arable land is concerned) of development of agricultural economy. The highest indices of this kind (the national average being $0,5 \mathrm{ha}$ ) are noted in the East and Nort-East of the country (Eomża voivodship $1.31 \mathrm{ha}$ ). High indices are also found in the voivodships of Central Poland and of Lakelands, whereas low indices are found in the Southern part of the country (enormous overpopulation in the past), in the South-West and in voivodships of Warsaw $(0.08$ ha per one inhabitant - the lowest index in the country), of Łódź, Gdańsk and Poznań (Fig. 6). A small area of arable land per one inhabitant is undoubtedly an expression of a high level of urbanization of a given voivodship, including rural areas.

Clearly differentiated in respect of area is also a social aspect of urbanization. In this sphere the amount of services sold (thousands zlotys) per one inhabitant, dwelling resources (number of rooms by 1000 inhabitants) and a number of newspapers sold in one year per 1 inhabitant of voivodship are considered. The first two indices characterize differentiation of satisfaction of basic social needs, the third one provides certain view on intensity of interest in social problems, and intensity of the flow of information ${ }^{5}$.

\footnotetext{
5 To determine differentiation of social aspect of urbanization it would be desirable to investigate a "city lifestyle". The way of leisure-time spending, membership in various social organizations, way of nutrition etc. These features are generally difficult to be measured, and besides they are not to be found in the official statistics.
} 


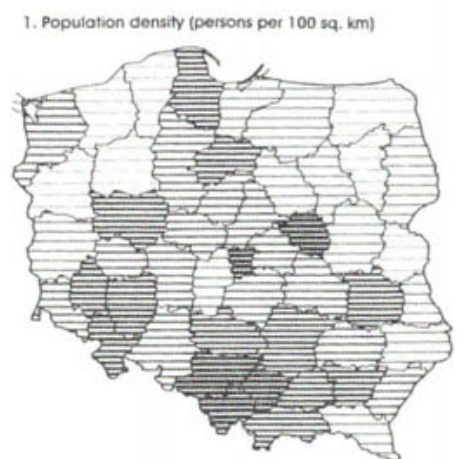

5. Capital goods

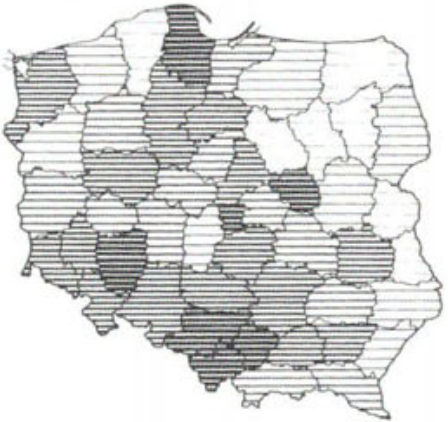

9. Number of newspapers sold per one inhabitant?

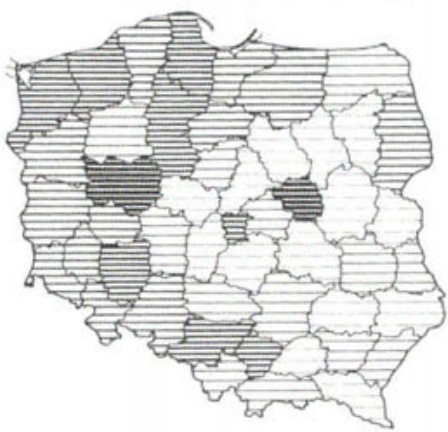

2. Percentage of urban population

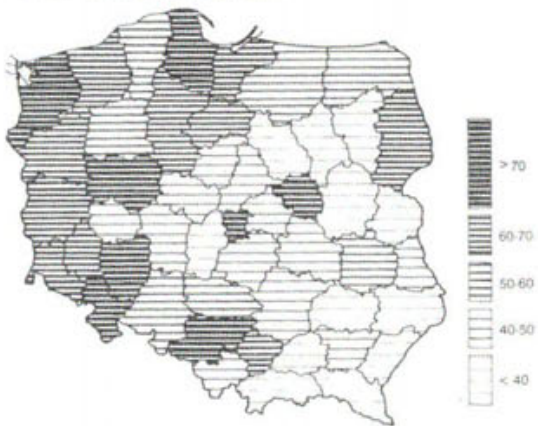

6. Arable land tha per inhobitant)

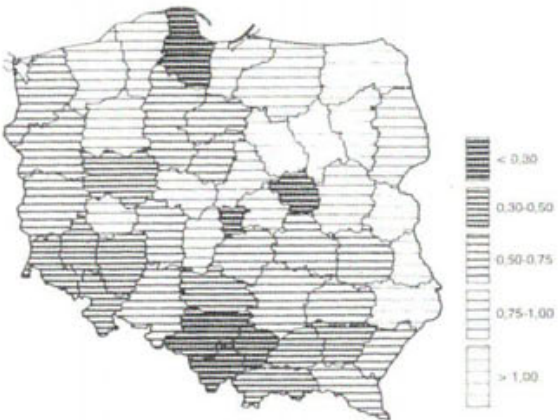

10. Area served by one town in sa. $\mathrm{km}$

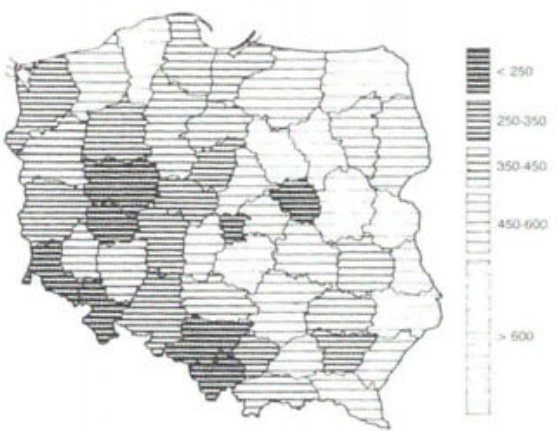

The spatial distribution of these three indices is characteristic. Voivodships situated in the Western part of the country (to the West from the line Elbląg Konin - Cracow) are characterized by higher indices in comparison with voivodships situated to the East from that line. In the Eastern part, higher indices are found only in Warsaw and Łódź voivodships. The most clear and distinct is a 

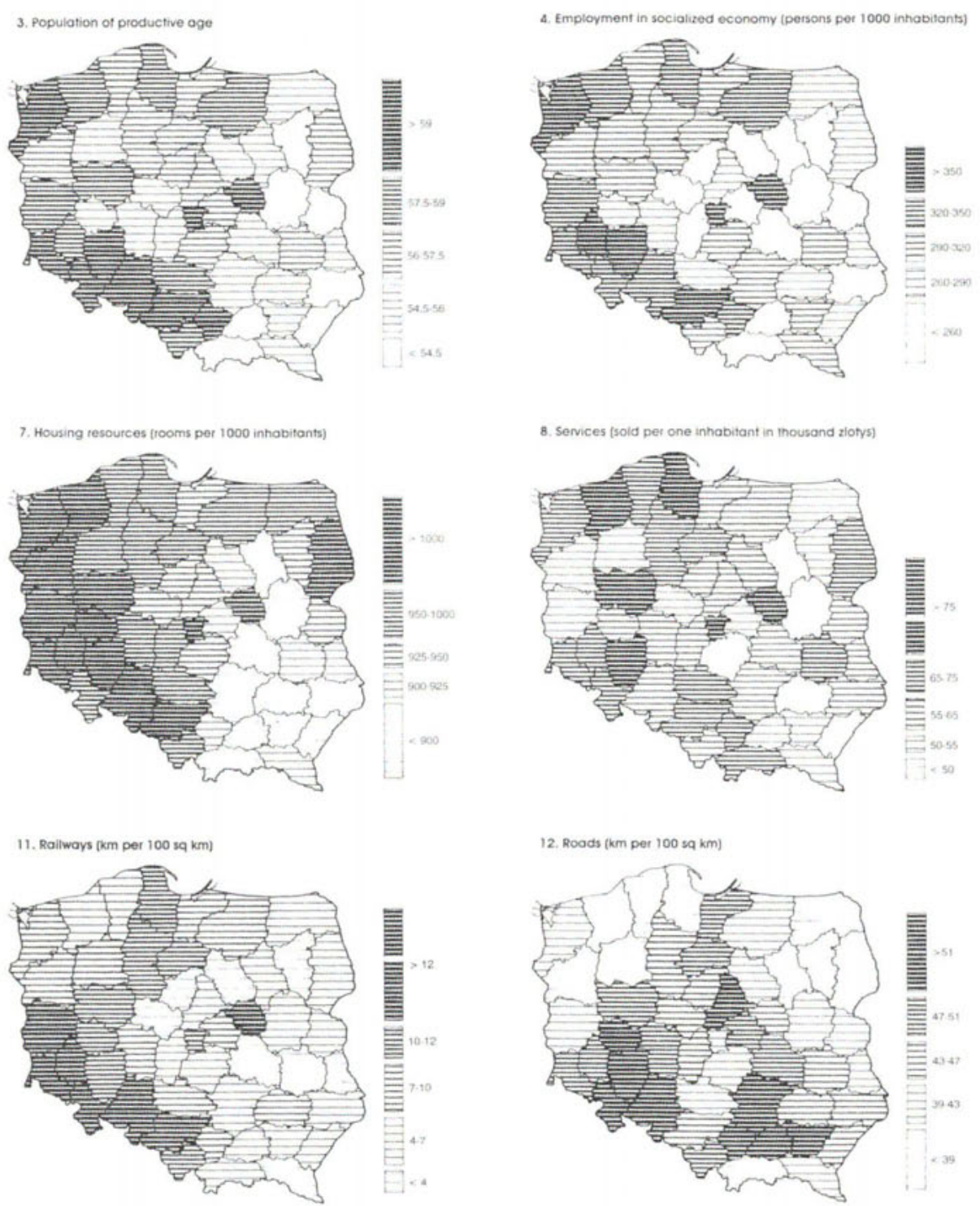

picture of spatial differentiation with regard to housing resources (Fig. 7), but more veiled, as if obliterated and slightly mosaic in respect of the two remaining indices (Fig. 8 and 9). Reasons for the existing territorial distribution of indices showing the social aspect of urbanization should be looked for in the level of economic development of the particular parts of Poland, which is rooted in the historical past. The Western part of the country incorporated in the past in the German (Prussian) State, stepped on the road of rapid development of capitalist 


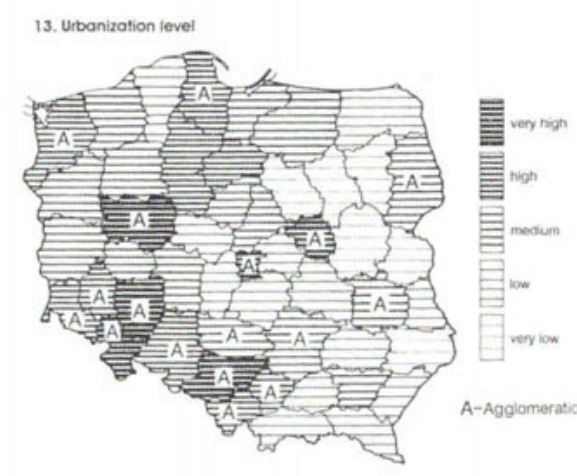

economy earlier and attained a higher level of this development. On the other hand, in the areas of the present-day Central and Eastern voivodships which were governed by Russia nad Austria capitalist forms of economy developed later, feudal relics existed longer, and economic development attained a lower level.

The level of urbanization in the spatial aspect is evidenced by a municipal network density coming from the number of towns and expressed by the index of an average area "serviced" by one town, or the index of an average distance between towns, as well as accessibility by transportation means defined with the use of indices of railroad density and density of hard-surface roads.

The towns in Poland are located irregularly; on the average, one town "services" an area slightly over $370 \mathrm{~km}^{2}$. The range of this index is considerable. In Wałbrzych voivodship where the town network is the most dense one, one town "services" on the average $134.5 \mathrm{~km}^{2}$, whereas in the voivodship having thin town network i.e. in Zamosc voivodship, this index exceeds 997 (Fig. 10). The spatial differentiation is a consequence of economic development and of transformation of the settlement status occurring in the past, as well as ove the past forty-five years. In the voivodships situated in the territory under the former Russian Partition, a rare network of towns is a consequence of political restrictions (taking away municipal rights from many settlements) applied by Russian authorities after the fall of the January Insurrection of 1863. In the area of the former Prussian Partition no such things happened, and there also existed a more dense network of towns - centres of agricultural regions. In the areas of the former Austrian Partition, no essential changes have been observed over the past one hundred years.

A distribution of capitalistic attitudes and behaviour characterstic of urbanized areas, links of towns with their hinterland, flow of people to towns and transmission of urban norms and systems of values to the rural areas which entailed urbanization of the rural area, are facilitated by a well-developed railway network and the network of hard-surface roads. As far as the density of railway network is concerned (Fig. 11), considerable density is found in the area of Upper and Lower Silesia, voivodships of Wielkopolska area and of Eastern Pomerania, Warsaw and Łodź voivodships. On the other end, namely of the thinnest network, are voivodships of Łomża and Ciechanow, Włocławek, Konin and Chełm, Lublin and Radom, as well as Krosno. Among them prevail areas of the proverbial transportation void on the periphery of the former Russian Empire and Austro-Hungarian Empire. 
On the other hand, a network of roads of hard surface is more dense in the areas of voivodships of Lower Silesia, South Wielkopolska and a majority of voivodships of the Carpathian Highland, as well as in voivodships of the Central Poland (Fig. 12), but - significantly - neither Warsaw nor Łódź voivodships. Also, a considerably thinner network of hard-surface roads is characteristic of the North-Eastern Poland, voivodships of Pomerania (Szczecin voivodship excluding) and voivodships of Eastern Poland, although here this phenomenon is not so conspicuous.

In effect of investigations it can be stated that, generally, a degree of urbanization of individual voivodships is considerably differentiated (Fig. 13). In six voivodships (Warsaw, Katowice, Łódź Walbrzych, Wrocław and Poznań) it is very high (the majority of features reach the highest indices in Poland), and in ten - high, in fifteen voivodships the level of urbanization is average, in thirteen - low and in six mainly situated in Eastern Poland - very low.

A characteristic feature is that voivodships of very high and high level of urbanization have urban agglomerations in their areas. There are agglomerations also in areas of four voivodships of an average level of urbanization (Bialy-stok, Częstochowa, Kielce, Lublin). These four voivodships are likely to attain a high level of urbanization soon.

The picture of spatial differentiation of urbanization level presented with the use of the method adopted differs quite clearly from the picture of urbanization determined only on the basis of share of urban population in the overall population of the voivodships. It is worth underlining that the method applied which permits to take into account more features of urbanization, reveals differences in a degree of urbanization of the particular voivodship on the one hand, and on the other seems to level these differences. 
